\title{
Improving red clover persistence under grazing
}

\author{
J.L. FORD and B.A. BARRETT \\ AgResearch Grasslands Research Centre, Private Bag 11008, Palmerston North, New Zealand \\ john.ford@agresearch.co.nz
}

\begin{abstract}
Red clover (Trifolium pratense L.) offers a number of advantages as a forage legume, but is constrained by poor persistence under grazing. The objective of this research was to test the growth and persistence of 18 populations among a wider set of 142 New Zealand and overseas accessions of red clover, in a mixed-sward replicated plot trial under rotational grazing by cattle in the Manawatu. We also measured plant morphological trait expression in a row trial using samples of the same red clover populations evaluated in the plot trial. Most red clover populations showed a marked decline in growth score after two years under grazing. The new variety 'Grasslands Relish' showed significantly $(\mathrm{P}<0.05)$ higher growth and persistence than all other entries over the three and a half years of the trial. After three and a half years under grazing, $60 \%$ of the 'Grasslands Relish' plants were alive, more than any other entry, and significantly $(\mathrm{P}<0.05)$ more than any commercial cultivars in the trial. Traits observed in the row trial were weakly to moderately correlated with performance in the mixed sward trial. Variation among growth habit in the row trial was the best predictor of performance in the three and a half year mixed sward trial $\left(\mathrm{R}^{2}=0.50\right)$. This research identifies a new red clover cultivar with potential for high growth and improved persistence under cattle grazing, and demonstrates the value of global genetic resources for improving the genetic merit of forages available in New Zealand.
\end{abstract}

\section{Introduction}

Forage legumes offer the potential to increase intake and feeding value of pasture, to lift animal production, to complement seasonal growth of grasses, and to improve product quality (Cosgrove et al. 2003; Hutton et al. 2011; Steinshamn 2010). They also fix atmospheric nitrogen $(\mathrm{N})$ in the soil and reduce parasite loads in ruminants (Abberton et al. 2006; Marley et al. 2005).

Persistence of sown forage is a primary driver of farm profitability (Brazendale et al. 2011). Plant breeding efforts have focused on improving persistence and production of forage legumes for New Zealand farm systems. Efforts in white clover have proven successful (Caradus et al. 1997; Widdup \& Barrett 2011), and international efforts to improve the persistence of lucerne under grazing have shown substantial gains (Bouton \& Gates 2003; Sewell et al. 2011; Smith et al. 2000). Efforts to improve the yield and persistence of red clover have focused independently on silage systems and grazing systems, and have been successful to varying degrees (Boller 2000; Rumball et al. 2003). However, efforts to date under grazing have not been sufficient to make red clover viable in long term mixed swards or pure stands in most New Zealand grazing systems.

Red clover offers specific advantages to white clover, including improved $\mathrm{N}$ partitioning in the animal, and lipid protection in the rumen conferred by the stabilisation properties of poly-phenol oxidase (Ranst et al. 2011; Sullivan \& Hatfield 2006). Red clover is faster to establish (Moot et al. 2000) and more summer active, and its deeper rooted crown offers improved water extraction capacity in moisture limited conditions (Brown et al. 2005; Greenwood \& Sheath 1982). It is also more tolerant of pasture plant pests including the clover root weevil (Sitona lepidus) (Gerard et al. 2005). Despite these advantages, red clover has been constrained by poor persistence under grazing, relatively low seed yield potential (Clifford \& Scott 1989), and susceptibility to fungal diseases (Skipp \& Christensen 1990).

Efforts to improve the persistence of New Zealand red clover have focused on plant morphology and plant chemistry. Breeding efforts commenced in the 1930s, with the cultivars 'Grasslands Turoa' and 'Grasslands Hamua' the first two released. 'Turoa' was a specific selection for persistence under close grazing. The tetraploid variety 'Pawera' is a more recent release with improved persistence and resistance to insects and fungi conferred by phytoestrogens (Anderson 1973; Sutherland et al. 1980). Concerns about these oestrogenic compounds' impact on reproductive efficiency in ewes grazing red clover monocultures led to selection of new varieties with low and moderate levels of phytoestrogens. More recent work has focused on plant morphology, pursuing more profuse and finer stems, a more prostrate growth habit, and vegetative reproductive characteristics, in addition to reduced phytoestrogens (Hyslop et al. 1999). The first new cultivar of this type was 'G27' (Rumball et al. 
Table 1 Red clover establishment, growth score and survival under rotational grazing by cattle in replicated mixed sward plot trial at Aorangi Farm near Palmerston North, New Zealand. "Establishment" was scored from 1 (low) to 5 (high). "Growth scores" are the visual red clover yield scored prior to each grazing, from 1 (low) to 10 (high). "Survival" is the percentage of red clover plants surviving after three and a half years.

\begin{tabular}{|c|c|c|c|c|c|c|c|}
\hline \multirow[b]{2}{*}{ Entry } & \multirow[t]{2}{*}{ Establishment } & \multicolumn{5}{|c|}{ Growth Score } & \multirow[t]{2}{*}{ Survival (\%) } \\
\hline & & Year 1 & Year 2 & Year 3 & Year 4 & Mean & \\
\hline AberRuby & 3.0 & 4.8 & 5.2 & 2.3 & 1.3 & 3.6 & 10 \\
\hline AC Endure & 3.7 & 5.3 & 5.4 & 5.9 & 2.0 & 5.1 & 10 \\
\hline Broadway & 4.0 & 8.3 & 7.5 & 7.3 & 5.8 & 7.4 & 36 \\
\hline Claret & 4.0 & 4.1 & 4.5 & 4.0 & 1.5 & 3.9 & 4 \\
\hline Crossway & 3.7 & 7.0 & 7.2 & 5.7 & 3.5 & 6.2 & 21 \\
\hline $\mathrm{G} 27$ & 4.3 & 6.1 & 6.0 & 4.8 & 3.5 & 5.3 & 17 \\
\hline GF148 & 2.3 & 4.4 & 4.7 & 2.7 & 2.5 & 3.7 & 11 \\
\hline Grasslands Colenso & 3.0 & 7.2 & 4.9 & 3.3 & 0.8 & 4.3 & 17 \\
\hline Grasslands Pawera & 3.0 & 6.2 & 6.8 & 5.8 & 4.0 & 6.0 & 25 \\
\hline Grasslands Relish & 4.0 & 6.9 & 7.9 & 8.8 & 8.5 & 8.1 & 60 \\
\hline Grasslands Sensation & 3.7 & 4.2 & 4.5 & 3.3 & 3.3 & 3.9 & 12 \\
\hline Tuscan & 3.0 & 6.3 & 6.6 & 6.1 & 2.5 & 5.8 & 21 \\
\hline XCG128 & 3.3 & 8.2 & 8.2 & 7.7 & 4.5 & 7.6 & 27 \\
\hline XСР89 & 4.7 & 9.0 & 7.1 & 7.5 & 5.5 & 7.4 & 48 \\
\hline XEC124 & 2.3 & 4.4 & 4.7 & 2.7 & 2.5 & 3.7 & 5 \\
\hline XLC4 & 3.3 & 7.0 & 6.2 & 6.4 & 6.0 & 6.4 & 29 \\
\hline XLS5 & 4.0 & 7.3 & 7.7 & 7.0 & 6.5 & 7.2 & 48 \\
\hline XSP59 & 4.0 & 7.7 & 8.6 & 7.4 & 7.7 & 7.9 & 48 \\
\hline Mean & 3.5 & 6.5 & 6.4 & 5.7 & 4.2 & 5.9 & 22 \\
\hline LSD (5\%) & 1.3 & 2.2 & 1.9 & 2.2 & 2.6 & 1.7 & 21 \\
\hline
\end{tabular}

Table 2 Red clover growth and morphological data collected on plant rows grown at Grasslands Research Centre in Palmerston North, New Zealand during the 2007-2008 season. Traits were visually scored on a 1 (low) to 5 (high) scales except for "Habit" 1 (upright) to 4 (prostrate), "Flowering" 1 (low) to 4 (profuse), and "Growth" 1 (low) to 10 (high).

\begin{tabular}{lcccccc} 
& Growth & Density & Habit & Early Flower & Late Flower & Leaf Size \\
Entry & Score & Score & Score & Score & Score & Score \\
\hline AberRuby & 3.9 & 2.8 & 1.5 & 3.0 & 3.0 & 3.5 \\
AC Endure & 4.3 & 2.8 & 1.7 & 2.0 & 2.0 & 4.0 \\
Broadway & 4.6 & 3.5 & 4.0 & 3.0 & 4.0 & 2.0 \\
Claret & 4.9 & 3.7 & 1.8 & 0.5 & 2.5 & 4.5 \\
Crossway & 4.4 & 4.0 & 4.0 & 2.0 & 4.0 & 2.0 \\
G27 & 4.2 & 3.2 & 2.5 & 0.0 & 3.0 & 3.0 \\
GF148 & 4.2 & 3.8 & 3.7 & 2.5 & 4.0 & 1.5 \\
Grasslands Colenso & 4.3 & 3.8 & 2.3 & 2.0 & 2.0 & 3.5 \\
Grasslands Pawera & 3.9 & 3.7 & 3.0 & 0.0 & 1.5 & 3.5 \\
Grasslands Relish & 5.1 & 3.7 & 2.8 & 3.0 & 4.0 & 3.0 \\
Grasslands Sensation & 3.9 & 2.7 & 1.0 & 3.5 & 2.5 & 4.0 \\
Tuscan & 4.7 & 3.3 & 2.0 & 2.0 & 4.0 & 3.0 \\
XCG128 & 4.6 & 4.0 & 3.2 & 0.5 & 4.0 & 3.0 \\
XCP89 & 4.7 & 3.5 & 1.5 & 2.0 & 2.5 & 3.5 \\
XEC124 & 4.2 & 3.8 & 3.7 & 2.5 & 4.0 & 1.5 \\
XLC4 & 4.0 & 4.0 & 4.0 & 0.0 & 3.5 & 2.0 \\
XLS5 & 3.9 & 2.3 & 2.0 & 3.0 & 2.5 \\
XSP59 & 4.9 & 1.7 & 2.0 & 1.5 & 4.5 \\
\hline Mean & 4.4 & 3.5 & 2.6 & 1.8 & 3.1 & 3.0 \\
LSD 5\% & 1.4 & 1.0 & 0.8 & 1.9 & 1.9 & 1.2
\end{tabular}


Table 3 Formononetin levels as measured in row-bulked leaf samples in a replicated spaced plant trial at Grassland Research Centre in Palmerston North, New Zealand during the 2007-2008 season.

Formononetin

\begin{tabular}{lc} 
Entry & $(\% \mathrm{DW})$ \\
\hline Crossway & 0.06 \\
Grasslands Colenso & 0.18 \\
Grasslands Pawera & 0.27 \\
Grasslands Relish & 0.10 \\
Grasslands Sensation & 0.14 \\
Tuscan & 0.25 \\
\hline Mean & 0.17 \\
LSD 5\% & 0.12
\end{tabular}

1997), followed by 'Grasslands Sensation', 'Crossway' and 'Broadway' (Claydon et al. 2003; Rumball et al. 2003), all of which were lower in phytoestrogens than 'Pawera', and offered improved dry matter production and persistence. 'Tuscan' is another recent cultivar in the market in New Zealand, a medium leaf type bred for high yield and improved persistence.

International researchers have studied and improved persistence in variety development programmes (Christie \& Martin 1999), with particular value found in the Mattenklee germplasm source from Switzerland (Boller 2000). The majority of published international research on sources and mechanisms of persistence has focused on mechanical harvest and forage conservation rather than grazing, and mechanisms of persistence may differ for contrasting managements or when faced with different suites of biotic and abiotic stress factors.

Collections of improved and ecotype red clover germplasm accessions offer the opportunity to test performance of red clover over a wider genetic base, and identify types with superior performance and persistence under grazing. The aim of this research was to undertake the first major assessment of new red clover germplasm accessions and cultivars in New Zealand in more than 20 years, to identify promising material with improved growth and persistence under rotational grazing in mixed swards, to observe morphological variation among single row samples of the accessions, and to assess the relationship between traits observed in mixed swards with those measured under short term screening in rows.

\section{Materials and Method}

\section{Plant Genetic Resources}

This project assessed 142 red clover accessions. These included a collection of 99 experimental populations and cultivars brought into New Zealand in 2006, and 35 New Zealand derived breeding lines, including 16 $\mathrm{F}_{1}$ progeny lines developed by crossing ecotypes from countries including Portugal, Georgia, Yugoslavia and Turkey with elite New Zealand cultivars, and 19 synthetics including the new experimental variety 'Grasslands Relish' (GF219). Finally, eight commercial cultivars were included as controls. The data and discussion focuses on 18 of these accessions, including the most promising new experimental material within the wider germplasm assessment.

\section{Evaluation: Mixed Sward Plots Under Grazing}

A three-replicate mixed sward trial, managed under rotational grazing by cattle, was established at Aorangi research farm in the Manawatu plains in October 2007. Plants randomly sampled from each of the 142 accessions were raised as seedlings in a greenhouse during late winter 2007. The plants were grown on for 12 weeks before being transplanted by hand into a pure grass sward containing a mix of a tetraploid long-rotation ryegrass (cultivar 'Grasslands Ohau' with AR1 endophyte) and a short rotation ryegrass (cultivar 'Maverick GII') in early October. Plot size was $0.75 \mathrm{~m} \times 0.75 \mathrm{~m}$, with 16 representative plants per plot with $25 \mathrm{~cm}$ spacing between transplants. Interplot spacing was 1.5 metres. The trial design was a randomised complete block. All plots were assessed for plant establishment five weeks post-transplanting. Plant establishment in all the plots was successful and no replanting was required. Grazing commenced when pasture content was estimated at between 2600 and $3000 \mathrm{~kg} / \mathrm{ha}$. Residuals were between 1400 and 1600 $\mathrm{kg} / \mathrm{ha}$. Red clover plants were not allowed to set seed during the three and a half years of the trial.

Red clover growth scores, integrating clover content and yield estimates, were visually assessed in each plot. Trial assessments were completed prior to each grazing in the spring, summer and autumn. The growth score was assessed by ranking each plot on a scale of $1-10$, with $1=$ lowest red clover growth and $10=$ highest red clover growth at that time. Clover growth scores were collected on 15 occasions, prior to each non-winter grazing commencing January 2008 and concluding in February 2011. A single establishment score was noted in November 2007.

Weeds, including incursion of other clover species in the plots, were monitored over the life of the trial and managed through grazing. Fertiliser applications included $200 \mathrm{~kg}$ of urea $\mathrm{N}$ annually in equal portions during late July, mid November, February and May. The soil $\mathrm{pH}$ at the trial site was 5 , however, this was addressed by the application of lime. Superphosphate was also applied. Lime and superphosphate application 
were made at the rates used across the entire farm. The Olsen $\mathrm{P}$ of the trial area averaged 21.5 over the course of the trial. In June 2011 the trial was terminated. Grass was killed with a selective herbicide, and the number of surviving red clover plants was recorded for each plot.

\section{Evaluation: Spaced Plant Rows Under Grazing}

A single row trial, using a randomised complete block design with two replicates, was established at AgResearch Grasslands in Palmerston North during the 2007 - 2008 growing season. Samples from each of the 142 accessions were transplanted into a cultivated alluvial soil, with six seedlings transplanted at 10 $\mathrm{cm}$ spacing within each row, and $0.6 \mathrm{~m}$ between rows. Grazing was the only form of weed management in the trial.

The trial was maintained for one year. Prior to each grazing, plants were visually assessed for morphological traits on a row by row basis. A mob of wethers was used to graze the trial after each regrowth interval. Following grazing, the rows were topped to a height of $5 \mathrm{~cm}$. Traits assessed were Growth Habit (1= erect and $4=$ prostrate), scored in January, February and March; Flowering $(0=$ no flowering and $4=$ over 50 open flower buds) scored in January (early flowering on 5 weeks regrowth) and February (late flowering on 9 weeks regrowth); Growth $(1=$ low $10=$ high $)$ scored in January, February, March, May, August, October and November; Density $(1=$ open $5=$ dense $)$ scored in January, February and May; and Leaf Size $(1=$ small 5 $=$ large) scored in April.

\section{Plant Secondary Metabolites}

Leaf formononetin concentrations were measured for a replicated sub-set of six entries in the spaced plant trial, using a leaf from each of the six plants in each row to constitute a bulk sample. Samples from each field replication were freeze dried, ground to a fine powder, and analysed by high pressure liquid chromatography (HPLC) to quantify the levels of formononetin against a range of standards. An existing HPLC method (Protocol unpublished) was modified to allow rapid through-put screening of large sample numbers, by reducing run times from $65 \mathrm{~min}$ per sample to $5 \mathrm{~min}$ per sample. The rapid method was validated to ensure accuracy and precision.

\section{Data Analysis}

The grazing plot and row trial data were analysed independently. All data were analysed using Genstat to test for differences among entries for the range of traits measured. Summary data from a subset of entries are reported in this paper, focusing on the 18 most relevant entries for the New Zealand pastoral sector, including international comparators.

\section{Results}

Under rotational grazing by cattle in mixed swards, there were significant $(\mathrm{P}<0.05)$ differences among the 142 red clover accessions for growth score within individual years, and among the mean across the three and a half year evaluation (results not presented). Mean growth score for the entire trial across years was 4.8 out of 10, with a range from 1.4 to 8.0 among all entries.

Among the 18 accessions reported, establishment scores for transplanted material ranged from 2.3 for populations 'GF148' and 'XEC124', up to 4.3 for 'G27' (Table 1). Growth scores in the first year ranged from 4.2 for 'Sensation' to 8.3 for 'Broadway'.

Evaluation of plant performance under cattle grazing over time revealed a marked reduction in performance rank for most entries, with the mode of annual mean growth scores dropping from 7 in the first year to 3.5 in the fourth year. The range of growth scores increased from 4.1 in year one to 7.7 in the fourth year (Table 1).

'Grasslands Relish' was typical in terms of establishment and first year performance in the mixed sward trial, however it exhibited sustained growth scores and improved rankings over the duration of the trial. This accession was the top ranked for growth score in years 2 and 3 and the final year of the grazing trial, and was significantly better than all named varieties except 'Broadway' over the three and half years of data (Table 1).

At termination of the trial, plant counts revealed that mean plant survival over the 18 accessions was $22 \%$, and ranged from $4 \%$ for 'Claret' up to $60 \%$ for 'Grasslands Relish', which had a significantly $\mathrm{P}<0.05$ ) higher rate of survival under cattle rotational grazing than all other entries in the trial (Table 3).

The single year row trial under rotational sheep grazing revealed significant $(\mathrm{P}<0.05)$ entry effects for all traits measured. Among the accessions considered, mean yield scores ranged from 3.9 to 5.1, and mean density ranged from 2.7 to 4.0 (Table 2). A range of growth habits was observed, with 'Grasslands Sensation' being the most upright, and 'XLC4', 'Broadway', and 'Crossway' being the most prostrate. Five entries were late flowering. Leaf size under this management ranged from 1.5 for 'XEC124' and 'GF148', to 4.5 for 'Claret' (Table 2). Formononetin concentrations (\% DW) ranged from 0.06 for 'Sensation' up to 0.27 for 'Pawera'. 'Tuscan' was 0.26, with 'Grasslands Relish' significantly $(\mathrm{P}<0.05)$ lower than Pawera at 0.10 (Table 3). For the 18 entries reported, growth score was only weakly correlated $\left(\mathrm{R}^{2}=0.17\right)$ between the two contrasting trials during the first year. The correlation increased to $\mathrm{R}^{2}=0.32$ when the three and half year growth score means of the mixed sward trial were compared with the row trial growth score means. 
A moderate negative correlation $\left(\mathrm{R}^{2}=-0.42\right)$ was observed between leaf size in the row trial and growth score over three and half years in the mixed sward trial. Habit in the row trial was positively correlated $\left(\mathrm{R}^{2}=\right.$ $0.50)$ with growth score over the three and half years in the mixed sward trial, as was density $\left(\mathrm{R}^{2}=0.38\right)$.

\section{Discussion}

This research evaluated variation in key traits among a range of newly introduced red clover germplasm, together with cultivars currently available in New Zealand. The cattle grazing trial revealed extensive genetic variation for growth score and persistence, including a new cultivar 'Grasslands Relish' among other promising experimental populations.

A single year evaluation of material under row trial conditions was moderately predictive of performance in the mixed sward over the course of the three and a half year trial, and could be used as a general basis for assessment. However, the row trial data would not have identified the clearly superior persistence and performance of 'Grasslands Relish' in years 3 and 4 of the mixed sward cattle grazed trial. These results indicate the value of designing breeding strategies that are the closest possible proxy to an on-farm production environment, and evaluating populations in that system over time.

The value of testing a wide array of material, including access to international genetic resources, is also demonstrated. This broad genetic basis has allowed identification of populations with the potential to substantially increase growth and persistence relative to that currently available to farmers.

The mixed sward study showed 'Grasslands Relish' to be a red clover with markedly improved potential for persistence under rotational cattle grazing in medium and long rotation swards, and confirmed it has low levels of formononetin. The formononetin level of 'Pawera' was lower that prior reports (Rumball et al. 1997), however the relative ranking of material was maintained.

Further trials under a range of grazing managements, climates and soil types in and beyond the Manawatu, and assessment of plant health characteristics and seed yield potential, are needed to fully characterise the potential value this new variety offers to the pastoral sector of New Zealand, and to understand the mechanism of persistence. In is also noted that performance of the cultivars and experimental lines may differ under sheep grazing systems.

We expect that the availability of more persistent and productive red clovers such as 'Grasslands Relish' on farm will extend the animal production and resource efficiency benefits of red clover to the pastoral industries of New Zealand.

\section{ACKNOWLEDGEMENTS}

The authors thank the professional farm staff at AgResearch Aorangi and AgResearch Grasslands for assistance with running these trials, Mr. Zane Weber for assistance with genetic resources, Dr. Zulfi Jahufer for advice on data assessment, and Grasslands Innovation Ltd. for funding the ongoing red clover variety development programme at AgResearch.

\section{REFERENCES}

Abberton, M.T.; Fothergill, M.; Collins, R.P.; Marshall, A.H. 2006. Breeding forage legumes for sustainable and profitable farming systems. Aspects of Applied Biology 80: 81-87.

Anderson, L.B. 1973. Breeding a late-flowering tetraploid red clover for New Zealand. New Zealand Journal of Agricultural Research 16: 395-398.

Boller, B. 2000. Corvus and Pica: two new red clover cultivars of the persistent "Mattenklee" type. Agrarforschung 7: 484-489.

Bouton, J.H.; Gates, R.N. 2003. Grazing-tolerant alfalfa cultivars perform well under rotational stocking and hay management. Agronomy Journal 95: 1461-1464.

Brazendale, J.R.; Bryant, J.R.; Lambert, M.G.; Holmes, C.W.; Fraser, T.J. 2011. Pasture persistence: how much is it worth? NZGA Pasture Persistence Symposium. Grassland Research and Practice Series 13: 3-6

Brown, H.E.; Moot, D.J.; Pollock, K.M. 2005. Herbage production, persistence, nutritive characteristics and water use of perennial forages grown over 6 years on a Wakanui silt loam. New Zealand Journal of Agricultural Research 48: 423-439.

Caradus, J.R.; Clifford, P.T.P.; Chapman, D.F.; Cousins, G.R.; Williams, W.M.; Miller, J.E. 1997. Breeding and description of 'Grasslands Sustain', a mediumlarge-leaved white clover (Trifolium repens L.) cultivar. New Zealand Journal of Agricultural Research 40: 1-7.

Christie, B.R.; Martin, R.A. 1999. Selection for persistence in red clover. Canadian Journal of Plant Science 79: 357-359.

Claydon, R.B.; Rumball, W.; Miller, J.E. 2003. 'Grasslands Sensation' red clover (Trifolium pratense L.). New Zealand Journal of Agricultural Research 46: 355-357.

Clifford, P.T.P.; Scott, D. 1989. Inflorescence, bumble bee, and climate interactions in seed crops of a tetraploid red clover (Trifolium pratense L.). Journal of Applied Seed Production 7: 38-45.

Cosgrove, G.P.; Clark, D.A.; Lambert, M.G. 2003. High production dairy-beef cattle grazing systems: a review of research in the Manawatu. Proceedings of the New Zealand Grassland Association 65: 21-28. 
Gerard, P.J.; Crush, J.R.; Hackell, D.L. 2005. Interaction between Sitona lepidus and red clover lines selected for formononetin content. Annals of Applied Biology 147: 173-181.

Greenwood, P.B.; Sheath, G.W. 1982. Suitability of some pasture species within sub-humid areas of Otago. 2. Legumes. New Zealand Journal of Experimental Agriculture 10: 371-376.

Hutton, P.G.; Kenyon, P.R.; Bedi, M.K.; Kemp, P.D.; Stafford, K.J.; West, D.M.; Morris, S.T. 2011. A herb and legume sward mix increased ewe milk production and ewe and lamb live weight gain to weaning compared to a ryegrass dominant sward. Animal Feed Science and Technology 164: 1-7.

Hyslop, M.G.; Kemp, P.D.; Hodgson, J. 1999. Vegetatively reproductive red clovers (Trifolium pratense L.): an overview. Proceedings of the New Zealand Grassland Association 61: 121-126.

Marley, C.L.; Fraser, M.D.; Fychan, R.; Theobald, V.J.; Jones, R. 2005. Effect of forage legumes and anthelmintic treatment on the performance, nutritional status and nematode parasites of grazing lambs. Veterinary Parasitology 131: 267-282.

Moot, D.J.; Scott, W.R.; Roy, A.M.; Nicholls, A.C. 2000. Base temperature and thermal time requirements for germination and emergence of temperate pasture species. New Zealand Journal of Agricultural Research 43: 15-25.

Ranst, G.v.; Lee, M.R.F.; Fievez, V. 2011. Red clover polyphenol oxidase and lipid metabolism. Animal 5: 512-521.

Rumball, W.; Keogh, R.G.; Miller, J.E. 2003. 'Crossway' and 'Grasslands Broadway' red clovers (Trifolium pratense L.). New Zealand Journal of Agricultural Research 46: 57-59.

Rumball, W.; Keogh, R.G.; Miller, J.E.; Claydon, R.B. 1997. 'Grasslands G27' red clover (Trifolium pratense
L.). New Zealand Journal of Agricultural Research 40: 369-372.

Sewell, J.C.; Hill, R.D.; Reich, J. 2011. Persistence of grazing tolerant lucernes under Australian conditions. NZGA Pasture Persistence Symposium. Grassland Research and Practice Series 13: 187-190

Skipp, R.A.; Christensen, M.J. 1990. Selection for persistence in red clover: influence of root disease and stem nematode. New Zealand Journal of Agricultural Research 33: 319-333.

Smith, S.R. Jr; Bouton, J.H.; Singh, A.; McCaughey, W.P. 2000. Development and evaluation of grazingtolerant alfalfa cultivars: A review. Canadian Journal of Plant Science 80: 503-512.

Steinshamn, H. 2010. Effect of forage legumes on feed intake, milk production and milk quality - a review. Animal Science Papers and Reports 28: 195-206.

Sullivan, M.L.; Hatfield, R.D. 2006. Polyphenol oxidase and o-diphenols inhibit postharvest proteolysis in red clover and alfalfa. Crop Science 46: 662-670.

Sutherland, O.R.W.; Russell, G.B.; Biggs, D.R.; Lane, G.A. 1980. Insect feeding deterrent activity of phytoalexin isoflavonoids. Biochemical Systematics and Ecology 8: 73-75.

Widdup, K.H.; Barrett, B.A. 2011. Achieving persistence and productivity in white clover. NZGA Pasture Persistence Symposium. Grassland Research and Practice Series 13: 173-180 